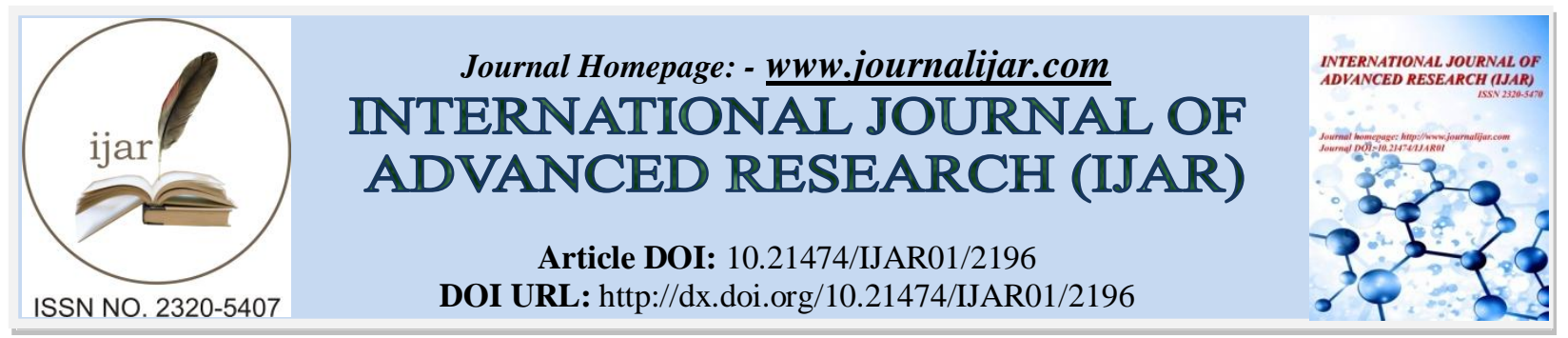

RESEARCH ARTICLE

\title{
A CROSS SECTIONAL SURVEY: KNOWLEDGE ON NEWBORN CARE AMONG PRIMI PARA MOTHERS.
}

Dr. P. Vetriselvi.

Assistant Professor, College of Nursing, JIPMER, PUDUCHERRY.

\section{Manuscript Info}

Manuscript History

Received: 27 September 2016

Final Accepted: 30 October 2016

Published: November 2016

Key words:-

Newborn care,knowledge,primipara mothers.

\section{Abstract}

Background and objective: The purpose of the study was to assess the level of knowledge on Newborn care among primipara mothers.

Material and methods:- A cross sectional design was used in the study. Population of the study comprised of 100 primipara mothers. Structured questionnaire comprising of 25 questions was used to collect the data. Responses to each question were statistically analyzed and the associations between different variables were established.

Results: Only $35 \%$ of the mother had adequate knowledge. A significant association was found between the knowledge and education of the women.

Conclusion: The study emphasized on the need of education towards newborn care among primipara mothers.

Copy Right, IJAR, 2016,. All rights reserved.

\section{Introduction:-}

Meherban Singh (2004), expressed that $80 \%$ of newborn

Babies require minimal care which can be provided by the mothers. It is desirable to keep the normal term babies with their mothers rather than in separate nursery. The health and survival of the newborn baby depends upon the health status of the mother and her awareness, education and skills in mother craft. Mothers look after her baby with love, affection and sense of sacrifice. Early involvement of the mother in the care of her baby is the best way to promote and encourage breast feeding.

Marilyn J. Hockenberry ( 2009 ), even though the parents have anticipated and prepared for child's arrival, they face the challenge of providing total care 24 hours a day for a new family member of the family. A crisis may occur as the event is perceived as disturbing old habits and eliciting new responses.

Shilpa and Shetyy ( 2011 ), the neonatal period apart from the old age, is perhaps the most hazardous period in a person's life, not only in developing countries but also in developed countries. The care of newborn in the family is governed by the families knowledge, awareness and cultural practices.

Mala L.C, traditional newborn care practices are there in all cultures since ancient times. Some of these traditional practices are still useful but some of these practices are dangerous thus the health of the newborn depends mainly on mothers knowledge and practice. Mothers knowledge and practice play a crucial role in safe guarding health and enhancing newborns adaptation to external environment. 
Shilpa G.S ( 2011 ), there is a lack of care in feeding, immunization, umbilical cord care, prevention of hypothermia among mothers. Mother is an important primary care provider and therefore her education will help to care for her infant. Thus the study will be helpful in providing the insights into the need of educating the primipara women attending the antenatal clinic.

Methodology: A cross sectional survey was conducted in post natal ward of a tertiary care centre. The study consisted of 100 primipara mothers. Inclusion criteria included primipara mothers who can understand and speak Tamil and willing to participate in the study. Exclusion criteria included primipara mothers who had psychiatric illness, who underwent caesarean section, whose baby is in neonatal intensive care unit and who lost their baby.

Sampling : convenient sampling was used.

Instruments: Subject data sheet had a set of questions that was oriented to the demographic data of subject. Knowledge on newborn care was assessed by using a questionnaire. The questionnaire had 25 multiple choice questions.

The data collection procedure : Data collection was started after getting ethical committee permission and permission from hospital authority. Informed consent was taken from study participants. Subject data sheet information and knowledge on newborn care was collected by the investigator through structured interview schedule. The time duration to complete the questionnaire was $25-30$ minutes.

Ethical considerations : Research proposal was approved by Institute Ethical Committee and permission from hospital authority was obtained. Informed consent was taken from study participants. Assurance was given to the subjects that anonymity and confidentiality will be maintained.

Data analysis : The distribution of background variables was expressed as frequencies and percentage. The knowledge were expressed as percentage. The association of mean knowledge score with different variables were evaluated using the $t$ test.

\section{Results :-}

* Out of 100 women participated in the study, the maximum numbers of the mothers ( $77 \%$ ) were in the age group of 18-25 years with regard to educational status, only $6 \%$ of the mothers were illiterate

* Regarding occupation eighty-five percent of mothers were housewives. As far as income is concerned seventy two percent of mothers family income was less than 5000 rupees.

* Regarding type of family, $61 \%$ were from joint family with regard to religion. $91 \%$ were Hindus. As far as domicile is concerned, $65 \%$ were from rural area.There is significant association between the level of knowledge and education and income of the participants.

* There is no significant association between the level of knowledge and other variables like age, occupation, type of family, religion and domicile.

Table 1: Level of knowledge of the Primipara Mothers regarding Newborn care

\begin{tabular}{|l|l|l|l|}
\hline KNOWLEDGE SCORE & FREQUENCY & PERCENTAGE & $\begin{array}{l}\text { LEVEL } \\
\text { KNOWLEDGE }\end{array}$ \\
\hline $0-50 \%$ & 4 & $4 \%$ & Onadequate \\
$51-75 \%$ & 61 & $61 \%$ & Moderately adequate \\
$76-100 \%$ & 35 & $35 \%$ & Adequate \\
\hline
\end{tabular}


TABLE 2: Knowledge scores of Primipara Mothersregarding Newborn care in relation to their demographic variables

\begin{tabular}{|c|c|c|c|c|c|}
\hline S.No. & Demographic Variables & Frequency & Mean & Standard Deviation & P Value \\
\hline \multirow[t]{3}{*}{1.} & AGE & & & & \\
\hline & $18-25$ years & 77 & 17.10 & 2.985 & $\mathrm{t}=-.103$ \\
\hline & $26-40$ years & 23 & 17.17 & 2.387 & $\mathrm{p}=.918$ \\
\hline \multirow[t]{7}{*}{2.} & EDUCATION & & & & \\
\hline & Illiterate & 6 & 14.50 & 3.209 & \\
\hline & Primary education & 27 & 16.33 & 2.542 & $\mathrm{~F}=2.417 *$ \\
\hline & Secondary Education & 31 & 17.45 & 3.139 & $\mathrm{p}=0.042$ \\
\hline & Higher Secondary Education & 15 & 17.47 & 2.774 & \\
\hline & Diploma & 9 & 18.78 & 1.856 & \\
\hline & Degree & 12 & 17.67 & 2.348 & \\
\hline \multirow[t]{3}{*}{3.} & OCCUPATION & & & & \\
\hline & Working & 15 & 17.60 & 3.418 & $\mathrm{t}=0.706$ \\
\hline & Not Working & 85 & 17.04 & 2.740 & $\mathrm{p}=0.482$ \\
\hline \multirow[t]{3}{*}{4.} & INCOME & & & & \\
\hline & $<$ Rs.5000 & 72 & 16.65 & 2.874 & $\mathrm{t}=-2.715^{*}$ \\
\hline & $>$ Rs. 5000 & 28 & 18.32 & 2.435 & $\mathrm{p}=0.008$ \\
\hline \multirow[t]{3}{*}{5.} & TYPE OF FAMILY & & & & \\
\hline & Nuclear & 39 & 17.08 & 3.421 & $\mathrm{t}=0.12$ \\
\hline & Joint & 61 & 17.15 & 2.442 & $\mathrm{p}=0.904$ \\
\hline \multirow[t]{4}{*}{6.} & RELIGION & & & & \\
\hline & Hindu & 91 & 17.10 & 2.860 & $\mathrm{t}=0.516$ \\
\hline & Christian & 8 & 17.00 & 2.878 & $\mathrm{p}=0.598$ \\
\hline & Muslim & 1 & 20.00 & - & \\
\hline \multirow[t]{3}{*}{7.} & DOMICILE & & & & \\
\hline & Rural & 65 & 16.88 & 3.023 & $\mathrm{t}=-1.166$ \\
\hline & Urban & 35 & 17.57 & 2.465 & $\mathrm{p}=0.247$ \\
\hline
\end{tabular}

Note: * indicates significant results

\section{Discussion:-}

This study findings showed that only $35 \%$ had adequate knowledge, $61 \%$ had moderately adequate knowledge and $4 \%$ had inadequate knowledge. There was an association between the mean knowledge score with education and family income, and other variables did not have the association.

The above findings were supported by the following studies. Mala 1.c.[2010] conducted a study to assess the knowledge of mothers on newborn care in mamipur.60 primipara mothers were interviewed. The results showed that $40 \%$ had inadequate knowledge, $14 \%$ had moderately adequate knowledge and 50\% had adequate knowledge.

\section{Conclusion:-}

The study was conducted to assess the knowledge level of Primpara mothers on newborn care. The results showed that only $35 \%$ of the mother had adequate knowledge. This emphasis our responsibility as a health educator. Moreover there is no significant association between level of knowledge and religion, type of family, domicile, age $\&$ occupation. This signifies the implementation of daily newborn care teaching in Antenatal and postnatal OPD's and wards.

\section{Reference:-}

1. Sharon.M.,Melanie. (2011). Infant Feeding Practices of Young Mothers. The American Journal of Maternal Child Nursing. 36(2):98-103.

2. Rashmi., Srikanta., Agarval RK, Gupta (2010). Skin care for the newborn, Indian Paediatrics, 47;593-598.

3. Meta-analysis of Evidence:UNICEF-PHFI Serious on Newborn and Child health, India, Indian Paediatrics, 48:537-546.

4. Panchali (2011). Massage Therapy In Infants An Evidence-Based Review, The Nursing Journal of India, CII (12): 270271.

5. Raji V (2005), Infants feeding patterns and risk of death and hospitalization in the first half of infancy: multicenter cohort study, Bulletin of the world health organization, 83(6): 418-424. 